\title{
Recent Developments in Engineering Measurements Lab
}

\section{Dr. Michael J. Schertzer, Rochester Institute of Technology (COE)}

Dr. Schertzer has held the position of Assistant Professor of Mechanical Engineering at RIT since the fall of 2013. His research interests involve droplet based microfluidic applications in point of care medical diagnostics, heat transfer, and energy generation. In addition to academic research, he has had the opportunity to consult and collaborate with industrial partners and government organizations in the areas of point of care medical diagnostics, public health, power generation, and heat management. He is the founding director of the Discrete Microfluidics Laboratory, co-director of the Knorr-Bremse Mechatronics Laboratory and co-director of RIT's Beyond 9.8 program. Dr. Schertzer is also serving as the vice-chair for the Micro and Nano Fluidics topic at the ASME International Mechanical Engineering Conference and Exposition 2015. Dr. Schertzer received a double major in Engineering and Management from the Department of Mechanical Engineering at McMaster University in Ontario, Canada. He also received his M.A.Sc. from McMaster for examining the heat transfer performance of capillary pumped loops in terrestrial and extra-terrestrial applications. He earned his Doctorate in the Department of Mechanical and Industrial Engineering at the University of Toronto for his work characterizing the motion and mixing of droplets in Digital Microfluidic Devices. He continued as a Postdoctoral Fellow at the University of Toronto where he focused on the design and commercialization of a point of care Digital Microfluidic device. During this time, Dr. Schertzer was also a sessional lecturer at Ryerson University (Toronto, ON) where he taught (1) Integrated Manufacturing and (2) Design of BioMEMS. Since joining RIT, Dr. Schertzer has had the opportunity to teach (1) Thermodynamics I, (2) Engineering Measurements Laboratory, and (3) Laboratory Applications in Mechatronics.

\section{Dr. Patricia Iglesias, Rochester Institute of Technology (COE)}

Dr. Patricia Iglesias Victoria is an Assistant Professor in the Department of Mechanical Engineering at the Rochester Institute of Technology. Previously she served as assistant professor at the National Technical Institute for the Deaf and as associate professor at the Polytechnic University of Cartagena, Spain. Her research focuses on wear and friction of materials, ionic liquids as lubricants, nanostructured materials and magnetic materials. She maintains an active collaboration with the research groups of Materials Science and Metallurgical Engineering at the Polytechnic University of Cartagena and Materials Processing and Tribology at Purdue University, Indiana. As a result of these collaborations, some of her articles have been published in important journals of her field of expertise and her article entitled "1-Nalkyl-3 methykimidazolium ionic liquids as neat lubricant additives in steel-aluminum contacts" has been named one of the TOP TEN CITED articles published in the area in the last five years (2010). Dr. Iglesias has extensive experience working on tribology and has published 14 peer-reviewed articles and more than 20 conference proceedings in the area.

\section{Ms. Kate N. Leipold, Rochester Institute of Technology (COE)}

Ms. Kate Leipold has a M.S. in Mechanical Engineering from Rochester Institute of Technology. She holds a Bachelor of Science degree in Mechanical Engineering from Rochester Institute of Technology. She is currently lecturer of Mechanical Engineering at the Rochester Institute of Technology. She teaches graphics and design classes in Mechanical Engineering, as well as consulting with students and faculty on 3D solid modeling questions. Ms. Leipold's area of expertise is the new product development process. Ms. Leipold's professional experience includes three years spent as a New Product Development engineer at Pactiv Corporation in Canandaigua, NY. She holds 5 patents for products developed while working at Pactiv. Ms. Leipold's focus at RIT is on CAD and design process instruction. She is a Certified ASME Geometric Dimensioning and Tolerancing Professional.

Prof. John D Wellin, Rochester Institute of Technology (COE) 


\title{
Recent Developments in Engineering Measurements Lab
}

\begin{abstract}
Over the past two years, the Engineering Measurements Lab has attempted to increase the breadth and depth of course material introduced to students to allow them to design and perform successful experimental tests. Over that time, the following structural changes have been made to this course: (i) a single lecture contact hour per week was added, (ii) lab contact hours focus more on practical aspects of each lab, and (iii) the number of experiments run in the course has increased from four to seven. To reflect these changes, the course has grown from one credit to two credits. Material for each lab was delivered in a two-week cycle with a one-hour lecture and two-hour lab period every week. Each lab had one dedicated lecture and additional lectures were added to further emphasize broader topics including data acquisition, measurement uncertainty, and statistical analysis.
\end{abstract}

In addition to the updated course content, the Toyota A3 report format has been adopted for all labs to expose students to a wider variety of tools for technical communication and to foster a spirit of creative and innovative problem solving. In keeping with the iterative nature of these reports, the general process for each lab involves multiple events with feedback from peers and instructors. During the week "A" lab period, students are introduced to the lab facility and perform an ungraded activity where they manually perform relevant calculations using a small subset of previously recorded data. They are then presented with a full set of previous data so they can perform relevant calculations and plot pertinent information. This prelab data exercise is submitted before the week "B" lab period. During the week "B" lab period, students run the laboratory to generate their own data set. A draft A3 report is then submitted prior to the following week "A" lab period. Students peer-review the draft A3 reports in lab before they perform the manual activity for the next laboratory. Final A3 drafts are due at 11:59 pm the following day. Lab topics for this course include characterization of (i) vortex tubes, (ii) vapor compression refrigeration, (iii) centrifugal pumps, and (iv) frictional pipe losses. New labs have been developed for this course examining (v) error propagation in measurement of complex geometries, (vi) measuring Poiseuille flow velocity profiles, and (vii) thermocouple calibration.

This work will describe the changes made to this course over the past two years and discuss their suitability based on effectiveness and student satisfaction. Plans for future development of the course will also be discussed. 


\section{Introduction}

A recent ABET self-study study report at the Rochester Institute of Technology focused on changes to the mechanical engineering curriculum during semester conversion identified Engineering Measurements Lab as an opportunity to develop a better understanding of (i) measurement techniques, (ii) experimental design, (iii) data acquisition, and (iv) sensors. These topics were formally covered in courses that were discontinued during conversion from quarters to semesters in fall of 2013. As part of that process, Thermo-Fluids Lab I has evolved into Engineering Measurements Lab. The goal of this change was to have students focus more on developing proper measurement techniques and experimental design.

The initial development of the Engineering Measurements Lab was described by the authors ${ }^{1}$. This course consisted of four guided labs and an independent study. The guided labs were similar to those administered in the past, but Toyota $\mathrm{A} 3$ report format ${ }^{2,3}$ was adopted in an effort to improve technical communication skills. This report format relies heavily on the development of high quality visual aids that can communicate the findings of an investigation on a single-sided A3 paper (11.7" x 16.5"). These reports force students to develop their ability to create information dense figures, which will also enhance their capacity to write traditional technical reports. Technical communication skills are often cited as one of the most desirable hiring criteria for graduates of engineering programs in the United States ${ }^{4,5}$. In initial offerings of Engineering Measurements Lab, students favored the A3 format to traditional lab reports ${ }^{1}$ but instructors felt that students could focus on aesthetic appeal at the expense of their technical understanding. Technical pre-lab activities were introduced in most labs to strengthen the technical rigor of the course.

In addition to a shift in focus, Engineering Measurements Lab has attempted to increase the breadth and depth of course material introduced to students so that they might better design and perform empirical tests. As such, the course has increased from one academic credits to two. This increased academic rigor is seen in the following changed in the course: (i) a single lecture contact hour per week was added, (ii) lab contact hours focus more on practical aspects of each lab, and (iii) the number of experiments run in the course has increased from four to seven. A lecture discussing theoretical and practical considerations for each experiment was developed and delivered before students performed the lab. Other lectures covering general experimental practices (i.e. propagation of uncertainty) or content related to labs that are in development (i.e. introduction to data acquisition systems) were delivered throughout the term.

As in the previous work, student feedback was collected at the conclusion of the semester (survey provided in Appendix A). Results from this survey are presented throughout this document. These survey results constitute all of the assessment data that are available at this time for the changes that have been made to the course. Specific assessment activities will eventually be incorporated to gauge the efficacy of the new components, consistent with general ABET assessment processes that are in place for the curriculum as a whole. However, because of the 
factors that originally motivated the changes to the course, it is certain that modifications will remain in some form or another, fine-tuned by whatever feedback is received by any formal assessments. The purpose of this discussion at this time is to outline what has been changed, and to present preliminary results.

\section{New Labs}

In this course, students performed a total of seven guided experiments. Four of these experiments were previously developed and have been run in this course for more than 10 years. A detailed description of these labs can be found in the previous work ${ }^{1}$. Three new experiments were developed specifically for this academic year: (1) Volume calculation, (2) Velocity profile in pipes and (3) Thermocouple calibration. Table 1 lists the seven lab experiments and the schedule for last fall semester, highlighting the three new additions.

Table 1. Lab Experiments and Schedule for the Semester

\begin{tabular}{|c|c|}
\hline Lab & Week \\
\hline Lab 1. Volume calculation & 2 \\
\hline Lab 2. Vortex tube & 4 \\
\hline Lab 3. Vapor compression refrigeration & $\mathbf{6}$ \\
\hline Lab 4. Centrifugal pumps & $\mathbf{8}$ \\
\hline Lab 5. Frictional pipe losses & $\mathbf{1 0}$ \\
\hline Lab 6. Velocity profiles in pipes & $\mathbf{1 2}$ \\
\hline Lab 7. Thermocouple calibration & $\mathbf{1 4}$ \\
\hline
\end{tabular}

In the second week of the semester, and after an introduction to measurement accuracy, error estimation, and error propagation, the students performed the first lab experiment: volume calculation. In this experiment, the students were given an aluminum block with different shapes (Fig. 1) to determine the mean value of the volume of the block with the corresponding uncertainty by three different methods:

1. Using a dial caliper to measure the lengths.

2. Measuring the water displacement when the block was immersed in water.

3. Weighing the block and using the material's density. 
The students were requested to report the range of possible values of the volume obtained by each method. Two types of errors were considered in the calculation: systematic and random errors $^{6}$. Systematic errors are the result of a mis-calibrated device and/or a measuring technique which consistently results in a larger or smaller measured value relative to the true value ${ }^{7}$. These types of errors are repeatable, biased and may be reduced if they are recognized in the measurement process. On the other hand, random errors are non-biased and can be addressed by statistical methods. A key aspect of this experiment was identifying and quantifying both random and systematic errors associated with each method.

The velocity profile in pipes experiment was developed to complement the frictional pipe losses investigation. A detailed description of the frictional pipe losses lab is presented in previous works ${ }^{1,8}$. In the velocity profile in pipes experiment, the students empirically determined the
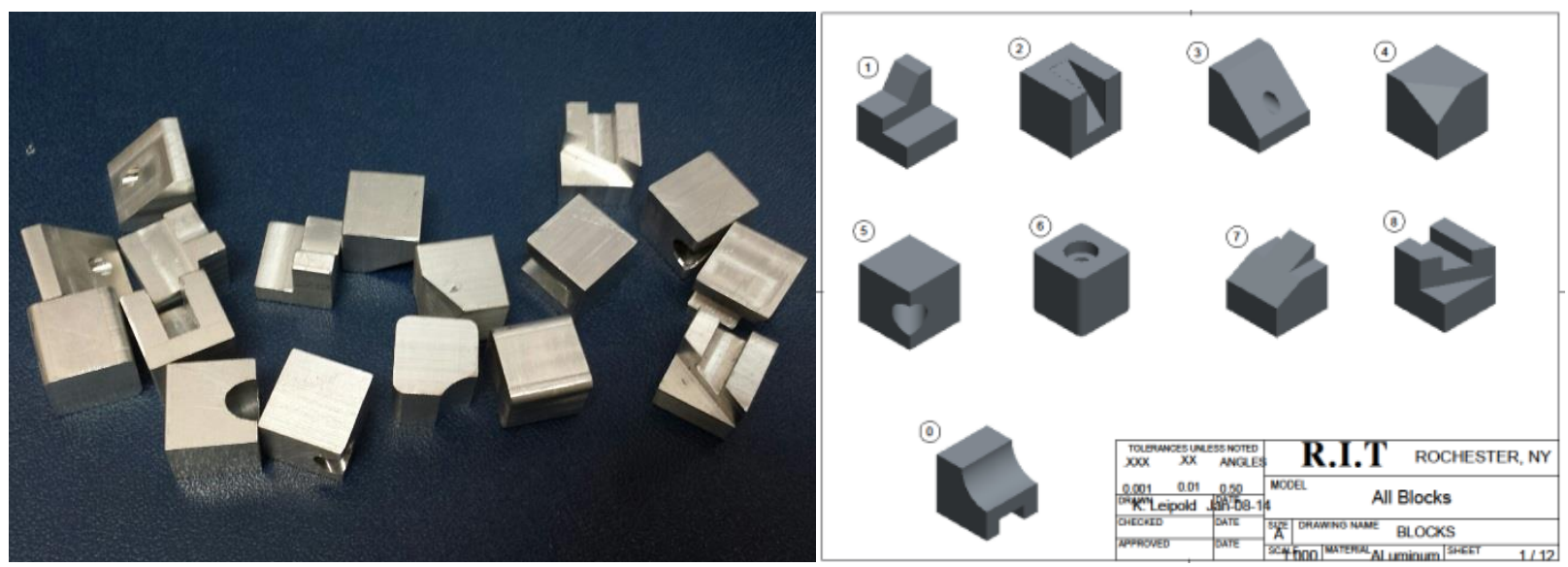

Figure 1. Aluminum blocks given to the students for lab 1: volume calculation.

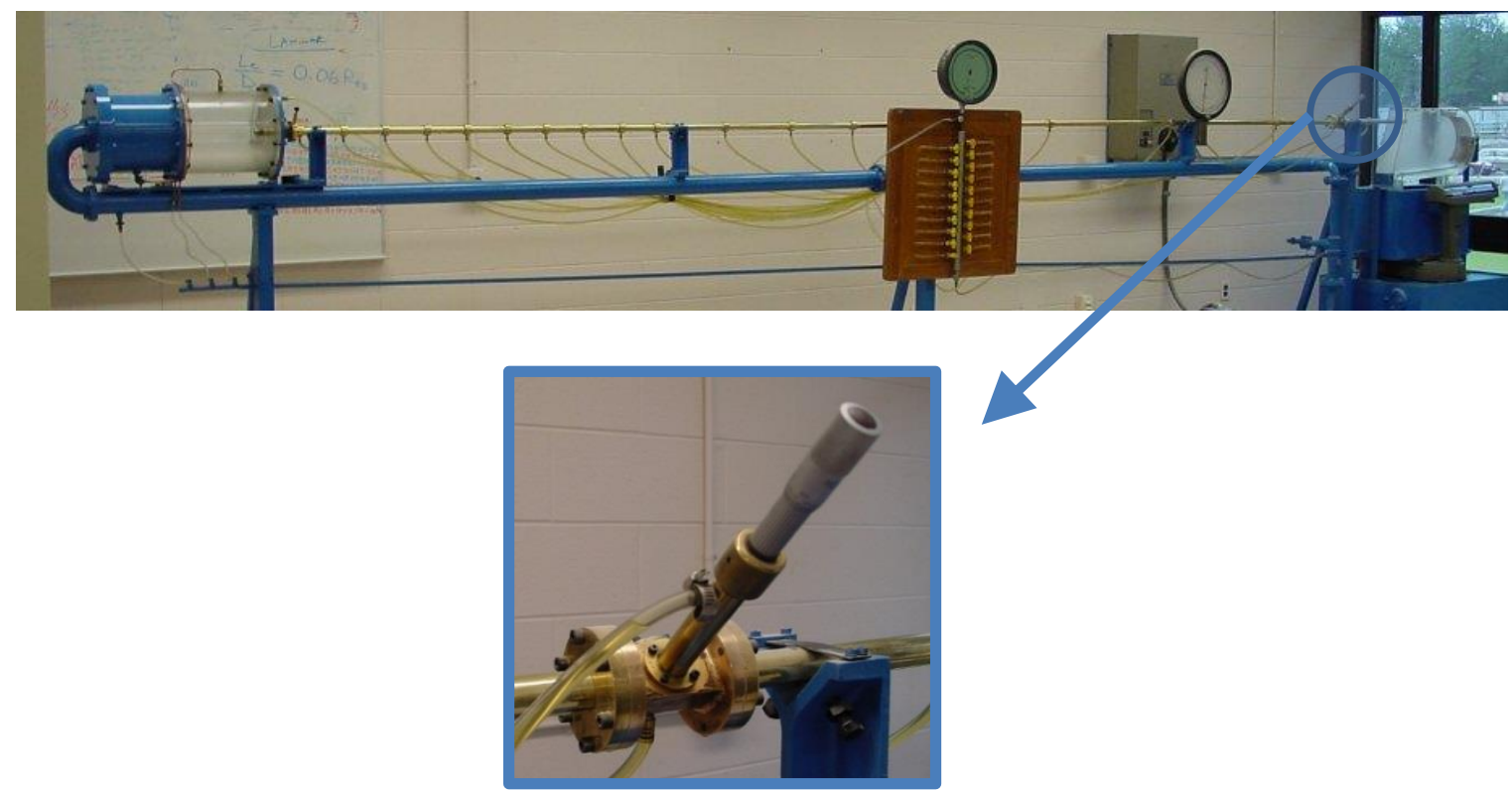

Figure 2. (a) Setup for frictional pipe losses and velocity profile in pipes labs; with (b) detail of Pitot tube. 
velocity profile of a laminar and turbulent flow in a round pipe using a Pitot tube (Figure 2) installed at the end of the pipe. The tube is positioned with a micrometer screw, allowing the measurement of the total pressure at different locations along the cross section of the pipe. The difference in total and static pressures is used with Bernoulli's equation to solve for the velocity at different points of the cross section of the pipe. The tube used in this course was manufactured and installed by Experimental Engineering Equipment Limited (Ontario, Canada). Students were also asked to discuss the general agreement between the measured and the theoretically documented velocity profiles.

In the last two weeks of the semester, students were introduced to the concept of data acquisition systems. The use of transducers for measurement and the acquisition of data with a computer were part of the lecture content. In the calibration of a thermocouple lab, students were asked to calibrate a k-type thermocouple. The experimental setup for the thermocouple calibration lab is shown in Figure 3. Students recorded the temperature of 10 different hot water and ice mixtures using a thermometer and the corresponding voltage output and plotted values on a VoltageTemperature graph. This information was used to determine the Seebeck coefficient and compare it to the value reported by the manufacturer.

At the end of each investigation, each group of students prepared a laboratory report for each experiment following an $\mathrm{A} 3$ report format that emphasized specific deliverables in each case. Samples of A3 reports of academic year 2014-2015 can be found in Appendix B.

Students were grouped in teams of two or three at the beginning of the semester, and all teams were maintained throughout the duration of the course. Since each member of the team was expected to contribute equally to each report, a group contribution indicator was required on each A3 report. This group contribution indicator is a graphical representation of each team

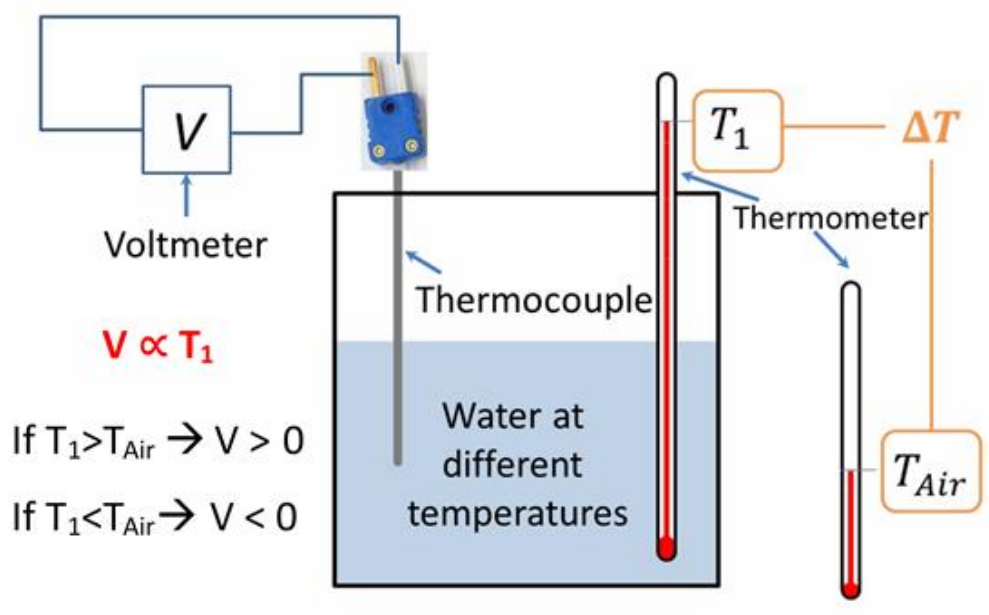

Figure 3. Thermocouple calibration setup showing the thermocouple and thermometer. 


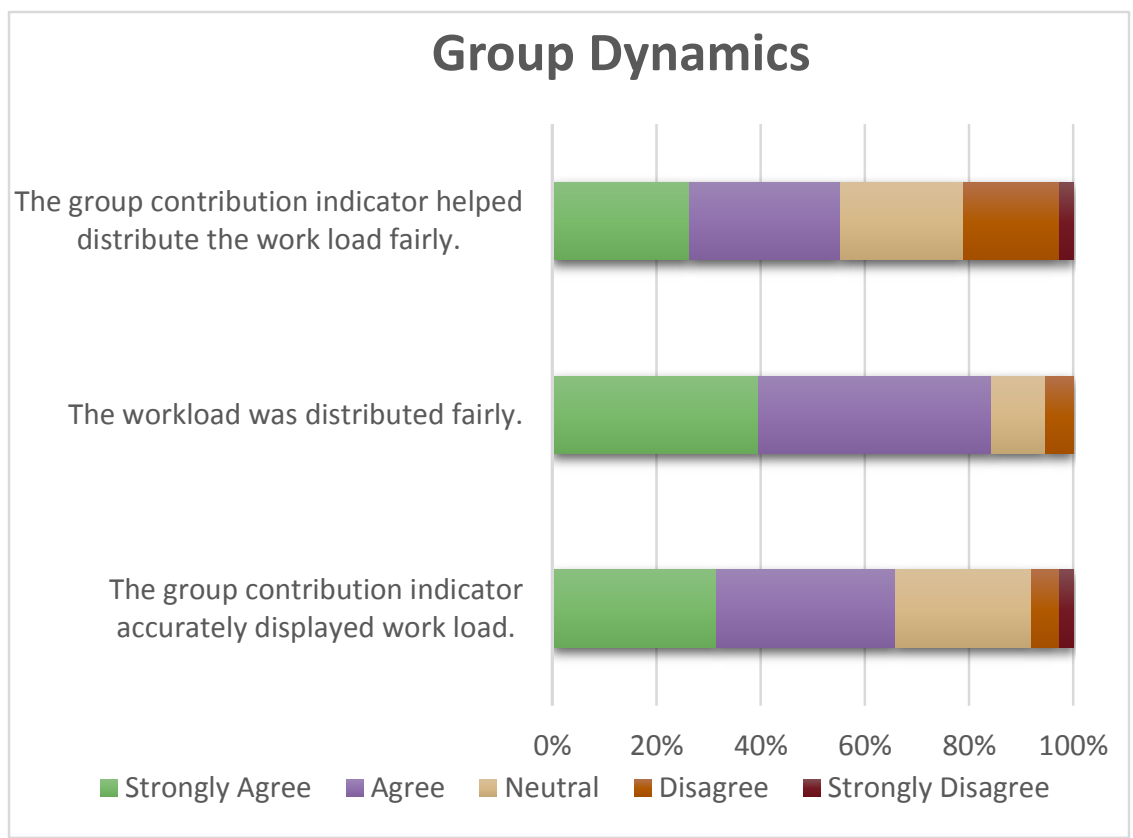

Figure 4. Results regarding the group dynamics.

member's percentage of work. A summary of survey results regarding group dynamics is presented in Figure 4. The majority of the students either agreed or strongly agreed that the group contribution indicator helped to distribute the work load fairly, and that it was an accurate representation of the work load.

\section{Lecture Content}

A single credit for lecture content was added to Engineering Measurements Lab as the result of a recommendation made in an ABET 2010 self-study. This lecture credit was added to provide students an opportunity to develop a better understanding of (i) measurement techniques, (ii) experimental design, (iii) data acquisition, and (iv) sensors. These topics were formally covered in courses that were discontinued during conversion from quarters to semesters in fall of 2013.

Eleven contact hours of lecture material was added to the course. Topics covered in these lectures are summarized in Table 2.

Lecture content designed for each lab focused mainly on theoretical principles, equipment selection, and operating principles of the equipment used in each activity. Content for these lectures was generally adapted from the instructional component of previous offerings ${ }^{1}$. Moving this content to course lectures allowed for the development and implementation of the pre-lab activities described in the following section.

As an example of added lecture content, students were given a brief overview of data acquisition systems in Lecture 10. This lecture outlined advantages and disadvantage of DAQ systems and gave an overview of the operation of a successive approximation analog to digital converter 
Table 2: Lecture Topics

\begin{tabular}{|c|l|}
\hline Lecture & \multicolumn{1}{|c|}{ Independent Study Topic } \\
\hline $\mathbf{1}$ & Measurement Error and Uncertainty (Cube Volume Lecture) \\
\hline $\mathbf{2}$ & Common Units and Conversions \\
\hline $\mathbf{3}$ & Vortex Tube Lecture \\
\hline $\mathbf{4}$ & Presentation of Data \\
\hline $\mathbf{5}$ & Vapor Compression Refrigeration Lecture \\
\hline $\mathbf{6}$ & Statistical Analysis and Representation of Uncertainty \\
\hline $\mathbf{7}$ & Centrifugal Pump Lecture \\
\hline $\mathbf{8}$ & Reynolds Pipe Flow 1: Pressure Drop and Entrance Length \\
\hline $\mathbf{9}$ & Reynolds Pipe Flow 2: Radial Pressure and Velocity Profiles \\
\hline $\mathbf{1 0}$ & Data Acquisition Systems \\
\hline $\mathbf{1 1}$ & Transducers Lecture \\
\hline
\end{tabular}

(Figure 5). A discussion of uncertainties and errors that arise in data acquisition due to quantization and aliasing was also included. This led to a discussion of design considerations regarding the number of bits and sampling frequencies of the system.

In addition to outlining the experimental procedure for the thermocouple calibration laboratory, the transducers lecture gave an overview of a broad range of industrially relevant sensors, the property they measure, and their principle of operation. A list of the transducers covered in this lecture is provided in Table 3.

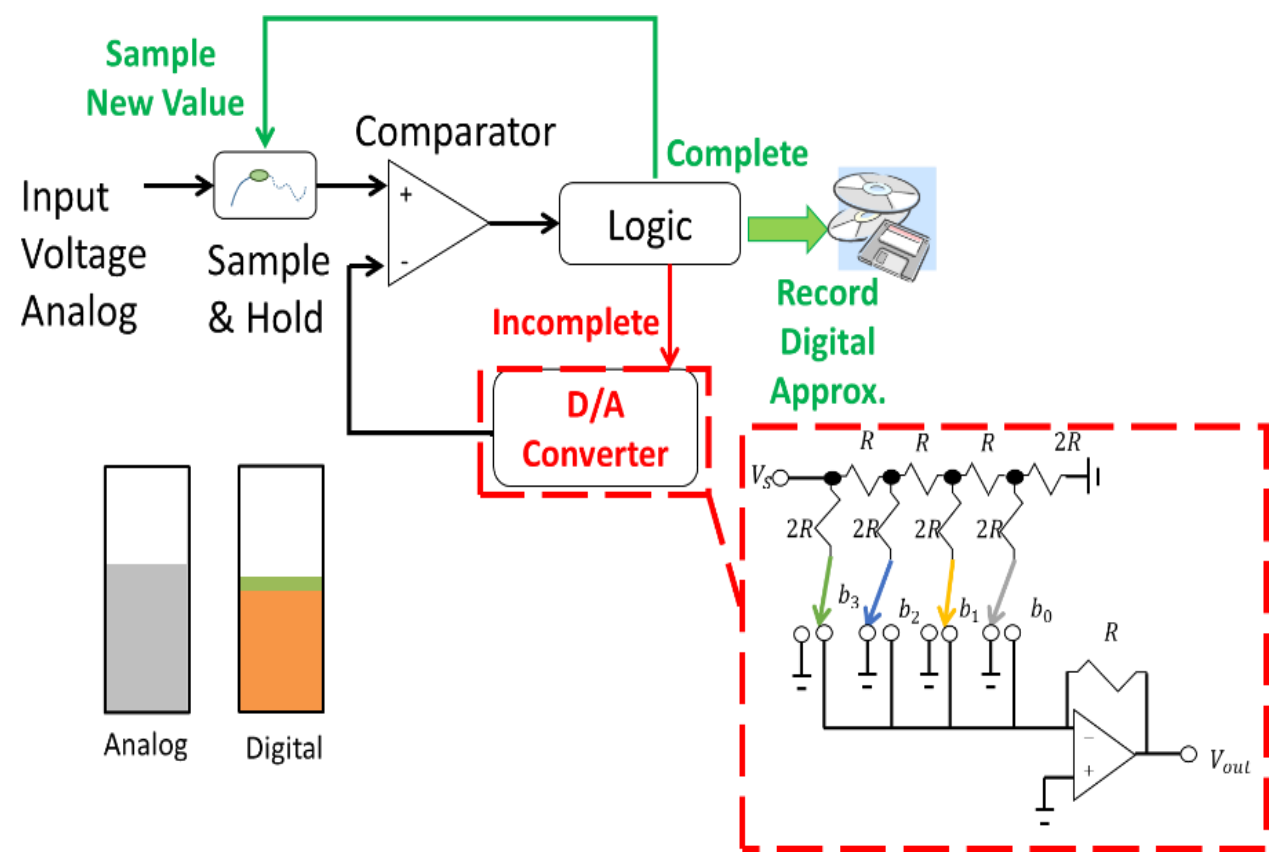

Figure 5. Sketch of a successive approximation analog to digital converter, and a digital representation of a $60 \%$ full scale analog signal. 
Table 3: Transducers

\begin{tabular}{|l|l|l|}
\hline \multicolumn{1}{|c|}{ Transducer } & \multicolumn{1}{|c|}{ Property of Interest } & \multicolumn{1}{c|}{ Measured Property } \\
\hline Thermometer & Temperature & Rise height \\
\hline Thermocouple & Temperature & Voltage \\
\hline IR Camera & Temperature & IR Radiation \\
\hline Manometer & Pressure & Rise height \\
\hline Bourdon Pressure Gage & Pressure & Spring compression \\
\hline Strain Gage & Pressure & Resistance \\
\hline Through Beam Sensor & Presence of an object & Light intensity \\
\hline Absolute Encoder & Radial position & Light intensity \\
\hline Potentiometer & Position & Resistance \\
\hline Incremental Encoder & Radial velocity / Direction & Pulse width / Phase shift \\
\hline Crystal Oscillator & Time & Voltage pulses \\
\hline Scale & Weight / Force & Compression \\
\hline Load Cell & Weight / Force & Deformation \\
\hline Vision System & Presence / Shape & Bit depth of multiple pixels \\
\hline Atomic Force Microscope & Texture & Deformation \\
\hline
\end{tabular}

While these lectures provide an introduction to data acquisition and sensor selection, future offerings will include lecture and lab content on implementation. Instructors have discussed having student repeat a labs after implementation of data acquisition so they have hands on experience on advantages and disadvantages of these systems.

Since lecture content was introduced in fall of 2014 and some of the delivered content was not formally tested, students were given credit for attending lecture as a component of a personal responsibility grade. Average lecture attendance was $94 \%$. This appears to be driven by the personal responsibility grade associated with lecture attendance (Figure 6). While $87 \%$ of respondents felt that they were adequately prepared for labs, only $50 \%$ agreed that the lectures were useful in laboratory preparation (Figure 6). This result is somewhat expected as portions of the lecture content was not specifically geared toward lab preparation. However, understanding of some lecture content (i.e. introduction to data acquisition) was not tested in the course. To stress the importance of the lecture material, instructors are considering implementing graded events, such as on-line quizzes, for content covered in lectures. The implementation of data acquisition in one of the lab activities will allow students the opportunity to actively learn this material. 


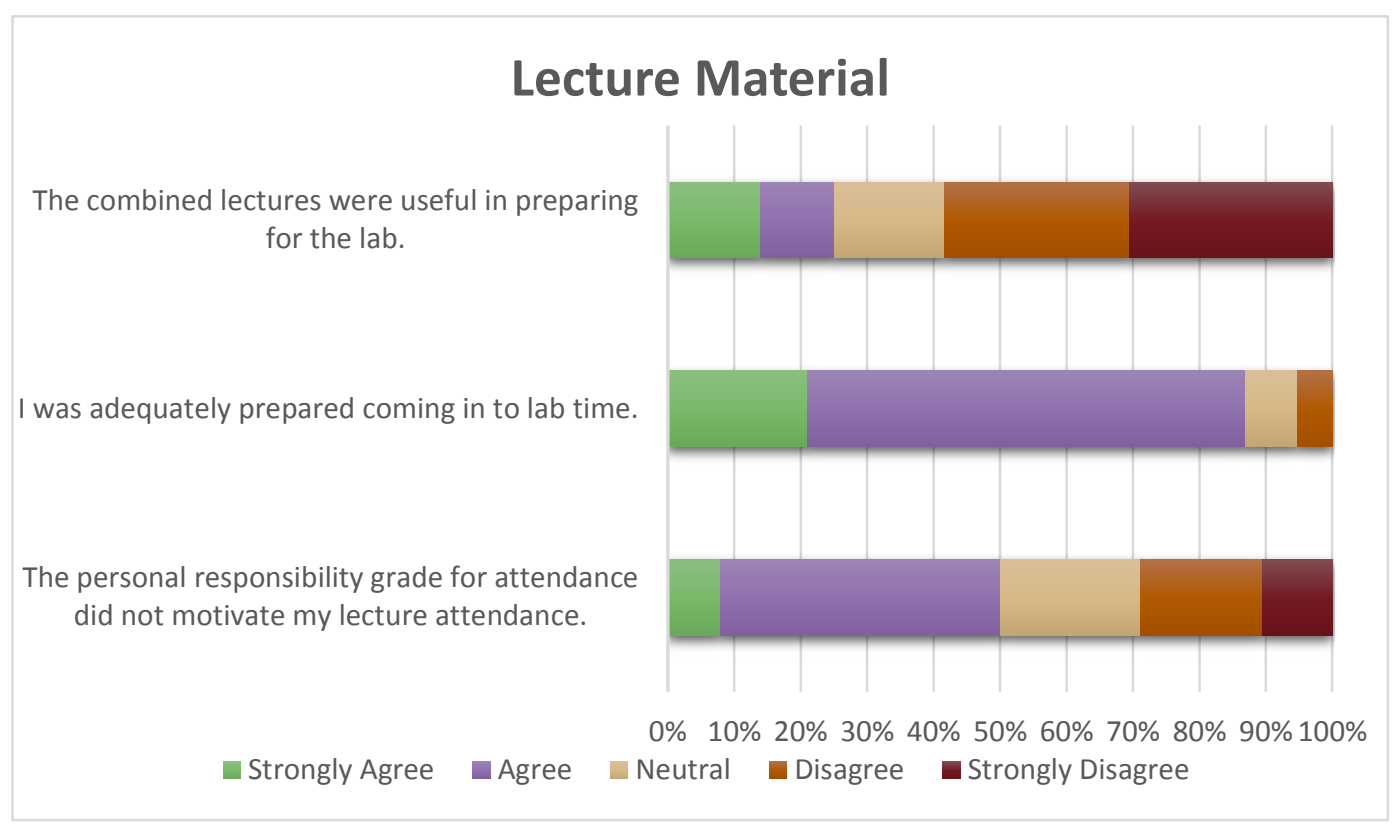

Figure 6. Results regarding lecture material

\section{Prelab Activities}

In previous offerings, students performed data analysis and report generation after completing the lab. While two weeks were scheduled between labs, the vast majority of the effort occurred in the second week. To help distribute the work more evenly, two sample calculations were added in the first week of the lab cycle. A small data set was calculated, typically by hand, in lab during the "A" week meeting. For homework, students processed an expanded data set from a previous semester. Students used that data to develop functional spreadsheets to perform the required analysis on their new data. Examples of both prelabs for the centrifugal pump are shown in Appendix C.

\begin{tabular}{|c|c|c|c|c|}
\hline Criteria & $\begin{array}{l}\text { Great Effort } \\
5 \text { points }\end{array}$ & $\begin{array}{l}\text { Good Effort } \\
4 \text { points }\end{array}$ & $\begin{array}{l}\text { Some Effort } \\
2 \text { points }\end{array}$ & $\begin{array}{l}\text { Minimal Effort } \\
\text { O points }\end{array}$ \\
\hline Pre Lab Preparedness & $\begin{array}{c}\text { Spreadsheet } \\
\text { submitted. } \\
\text { Contains all data } \\
\text { supplied. } \\
\text { Includes functioning } \\
\text { tables with headers } \\
\text { and units. } \\
\text { Proper unit } \\
\text { conversions calculated. } \\
\text { Graphs include labels } \\
\text { and units. } \\
\text { Cells for input clearly } \\
\text { identified. }\end{array}$ & $\begin{array}{l}\text { Submitted } \\
\text { spreadsheet. } \\
\text { Missing } 1 \text { or } 2 \\
\text { aspects. } \\
\text { Will still need tweaking } \\
\text { to use appropriately. }\end{array}$ & $\begin{array}{l}\text { Data has been } \\
\text { entered, but tables are } \\
\text { missing labels and } \\
\text { units. Graphs } \\
\text { missing. } \\
\text { Submitted after lab } \\
\text { started. }\end{array}$ & $\begin{array}{l}\text { Pre Lab work not } \\
\text { submitted. }\end{array}$ \\
\hline Overall Score & $\begin{array}{l}\text { Great Effort } \\
5 \text { or more }\end{array}$ & $\begin{array}{l}\text { Good Effort } \\
4 \text { or more }\end{array}$ & $\begin{array}{c}\text { Some Effort } \\
2 \text { or more }\end{array}$ & $\begin{array}{c}\text { Minimal Effort } \\
\text { o or more }\end{array}$ \\
\hline
\end{tabular}

Figure 7. Rubric for prelab spreadsheet data. 
The prelab spreadsheet was required to be submitted before the students collected data for their experiment. An effort-based rubric was provided to ease grading (Figure 7). This submission was worth 5 points of their 40 point lab grade. The ability to have a meaningful conversation during the lab based on the struggles that occurred before hand greatly improved the quality of the data presented.

A strong majority (86\%) agreed or strongly agreed that the prelab spreadsheet aided in their ability to perform necessary calculations for their lab report (Figure 8). While not all students felt this effort should be graded, the instructional team saw improvements in the data included in reports after the graded spreadsheet was introduced. Additionally, the spreadsheets were an individual graded item, requiring all students to become familiar with the analysis.

While rough drafts were used in previous offerings ${ }^{1}$, they were not graded. As such, some rough drafts were essentially complete, while others were unsatisfactory. Instructors felt that the peer review of these reports was unfair, as unprepared groups had the opportunity to observe high quality documents before starting their process. Grading of the rough draft was included in an effort to remedy this issue. The rough draft grade is 10 points of the 40 point lab grade. The grading rubric is also dominantly based on effort.

With the implementation of the rough draft as a graded event, the quality of the rough draft has improved greatly. Additionally, students found the rough draft and peer review process to be

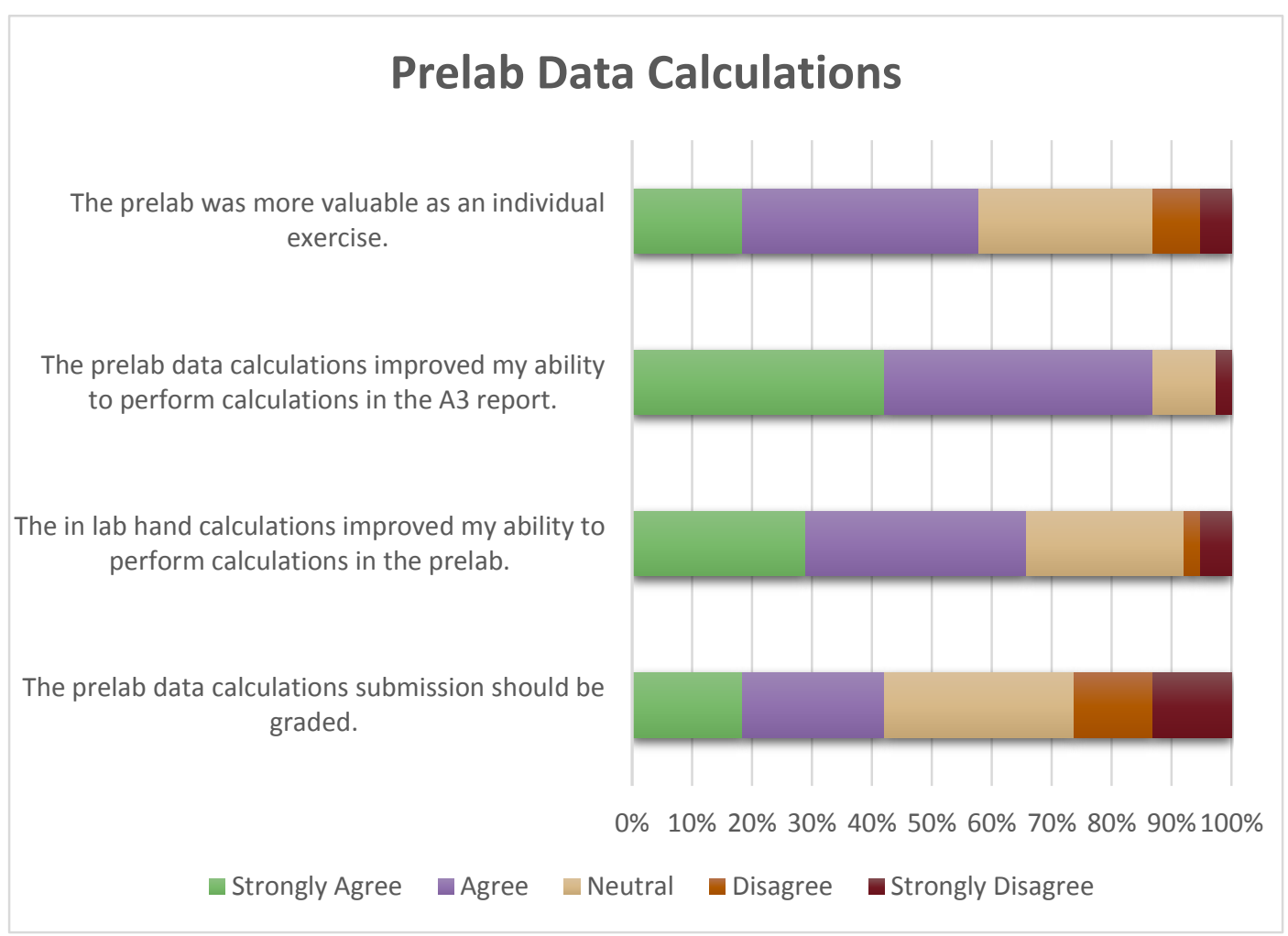

Figure 8. Results regarding prelab spreadsheets 
beneficial. One thought might be that even with graded rough drafts, teams would steal best practices from peers. It was observed that this is not the case. The teams took advice from peers and made modifications to their rough drafts, but teams did not simply copy other reports that they viewed.

Adding two graded events to every lab increases the grading load. A solution has been to grade the prelab spreadsheets and the rough draft during class. With spreadsheets due prior to lab, lab time, with students taking data, was adequate time to provide a quick grade and limited helpful feedback. For the rough drafts, groups were asked to spend 20 minutes providing peer feedback to two other groups. This time was also adequate to provide that quick grade and limited helpful feedback. Moving to a group submitted spreadsheet would help cut down on grading time, however it was previously observed that some students were not getting the hands on work of doing the calculations necessary, allowing their group mates to complete all the work.

\section{Conclusions}

1. Three new experiments have been successfully implemented in the Engineering Measurement lab to complement the already existing laboratories. In these new labs, students examined the following concepts: (1) error propagation in measurement of complex geometries, (2) flow velocity profiles in pipes, and (3) thermocouple calibration.

2. A group contribution indicator was required to be reported in each collected group activity to facilitate group dynamic. The majority of the students strongly agreed or agreed that the group contribution indicator helped to distribute the work load fairly, and that it was an accurate representation of the work load.

3. A lecture component was added to Engineering Measurements Lab in order to provide students an opportunity to develop a better understanding of (i) measurement techniques, (ii) experimental design, (iii) data acquisition, and (iv) sensors.

4. While students generally felt prepared for labs, many felt that the lecture content was not especially beneficial for this preparation. Instructors are working to better integrate new lecture topics into the laboratory experiments performed in this course.

5. The addition of the prelab activities was successful in helping to distribute the work, increase the quality of the submissions, and increased individual accountability. 


\section{References}

[1] Schertzer M.J., Iglesias-Victoria P., Leipold K.N., Wellin J.D. (2014); Enhancement of the engineering measurements laboratory for semester conversion; ASEE National Conference 2014; Indianapolis, IN.

[2] Shook J., 2009 “Toyota's Secret: The A3 Report”. MIT Sloan Management Review, http://sloanreview.mit.edu/article/toyotas-secret-the-a3-report/

[3] Leipold K., Landschoot T., 2009, "Utilizing an A3 report format for a technical review at the end of a cornerstone design course". ASME International Design Engieneering Technical Concferences \& Computers and Information in Engineering Conference 2009, pp. 1-11.

[4] Grose T. K., 2012 "Wow the Audience". ASEE Prism, http://www.prism-magazine.org/dec12/tt 01.cfm

[5] Nicometo C., Anderson K.J.B., Courter S., McGlamery T., Nathans-Kelly T., "Vital Skills in Engineering: Communication". School of Education: University of Wisconsin-Madison, http://www.cirtl.net/files/Communication.pdf

[6] Lindberg V., 2000, http://www.rit.edu/cos/uphysics/uncertainties/Uncertaintiespart1.html\#systematic.

[7] Gupta S.V., 2012, Measurement Uncertainties. Physical Parameters and Calibration of Instruments, Springer Berlin Heidelberg.

[8] Kandlikar S., Campbell, L.A, 2002. Effect of entrance conditions on frictional losses and transition to turbulence. ASME International Mechanical Engineering Congress \& Exposition, New Orleans, Louisiana

[9] Lavine, G., Landolfa, M., Mraz, R., 2014, "Reynold's Pipe Flow", Rochester Institute of Technology: MECE 211 - Engineering Measurements Laboratory.

[10] Doores, T., Greeley, J., Domos, B., 2014, “Thermocouple Calibration”, Rochester Institute of Technology: MECE 211 - Engineering Measurements Laboratory. 


\section{Appendix A: Student Satisfaction Survey Academic Year 2014-2015}

\section{ENGINEERING MEASUREMENTS LAB SURVEY}

Please provide your thoughts on some of the novel aspects of this lab.

\begin{tabular}{|c|c|c|c|c|c|}
\hline Statement & $\begin{array}{l}\text { Strongly } \\
\text { Agree }\end{array}$ & Agree & Neutral & Disagree & $\begin{array}{l}\text { Strongly } \\
\text { Disagree }\end{array}$ \\
\hline \multicolumn{6}{|l|}{ A3 Report } \\
\hline \multicolumn{6}{|l|}{ The A3 report was a good way to convey results. } \\
\hline \multicolumn{6}{|l|}{ There was adequate information provided on $\mathrm{A} 3$ formatting. } \\
\hline \multicolumn{6}{|l|}{ I preferred the $\mathrm{A} 3$ report format to a written technical report. } \\
\hline \multicolumn{6}{|l|}{$\begin{array}{l}\text { The A3 report format helped me prepare better figures that } \\
\text { could be beneficial on other report formats. }\end{array}$} \\
\hline \multicolumn{6}{|l|}{$\begin{array}{l}\text { The } A 3 \text { report format helped me focus on communicating key } \\
\text { results. }\end{array}$} \\
\hline \multicolumn{6}{|l|}{ The prelab data calculations should be graded. } \\
\hline \multicolumn{6}{|l|}{ The rough draft submission should be graded. } \\
\hline \multicolumn{6}{|l|}{ The peer feedback process should be graded. } \\
\hline \multicolumn{6}{|l|}{$\begin{array}{l}\text { The peer feedback was helpful in clarifying technical } \\
\text { problems or mistakes. }\end{array}$} \\
\hline \multicolumn{6}{|l|}{ The peer feedback I received was helpful. } \\
\hline \multicolumn{6}{|l|}{ Providing peer feedback was also beneficial. } \\
\hline \multicolumn{6}{|l|}{$\begin{array}{l}\text { The in lab hand calculations improved my ability to perform } \\
\text { calculations in the prelab. }\end{array}$} \\
\hline \multicolumn{6}{|l|}{$\begin{array}{l}\text { The prelab data calculations improved my ability to perform } \\
\text { calculations in the A3 report. }\end{array}$} \\
\hline \multicolumn{6}{|l|}{ The prelab was more valuable as an individual exercise. } \\
\hline \multicolumn{6}{|l|}{ I preferred collecting data via Google Forms. } \\
\hline \multicolumn{6}{|l|}{ Team Dynamics } \\
\hline \multicolumn{6}{|l|}{$\begin{array}{l}\text { The group contribution indicator accurately displayed work } \\
\text { load. }\end{array}$} \\
\hline \multicolumn{6}{|l|}{ The work load was distributed fairly. } \\
\hline \multicolumn{6}{|l|}{$\begin{array}{l}\text { The group contribution indicator helped distribute the work } \\
\text { load fairly. }\end{array}$} \\
\hline \multicolumn{6}{|l|}{$\begin{array}{l}\text { The Personal Responsibility grade for attendance did not } \\
\text { motivate my lecture attendance. }\end{array}$} \\
\hline \multicolumn{6}{|l|}{$\begin{array}{l}\text { The Personal Responsibility grade for attendance did not } \\
\text { motivate my lab attendance. }\end{array}$} \\
\hline \multicolumn{6}{|l|}{ The first A3 report on team dynamics was helpful. } \\
\hline \multicolumn{6}{|l|}{ I was adequately prepared coming into lab time. } \\
\hline \multicolumn{6}{|l|}{ Lectures } \\
\hline \multicolumn{6}{|l|}{ The combined lectures were useful in preparing for the lab. } \\
\hline The quality of the labs would be similar if led by TAs. & & & & & \\
\hline
\end{tabular}




\section{Appendix B: Sample A3 Reports of academic year 2014-2015,10}

\section{LAB \#4: Reynold's Pipe Flow}

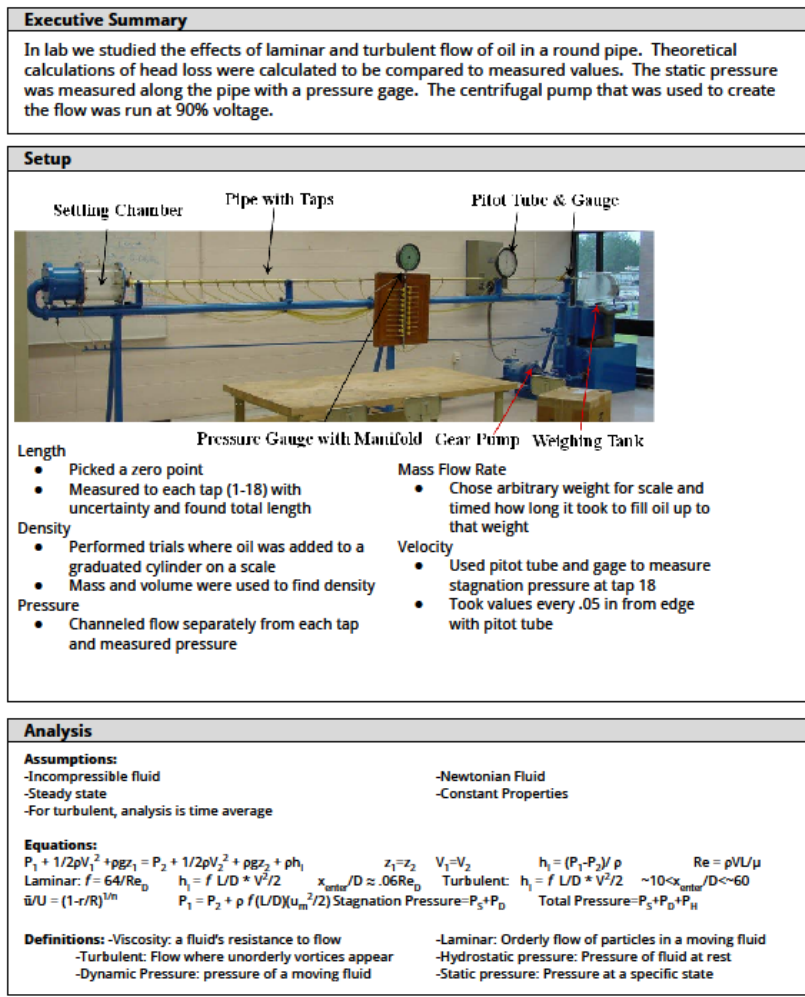

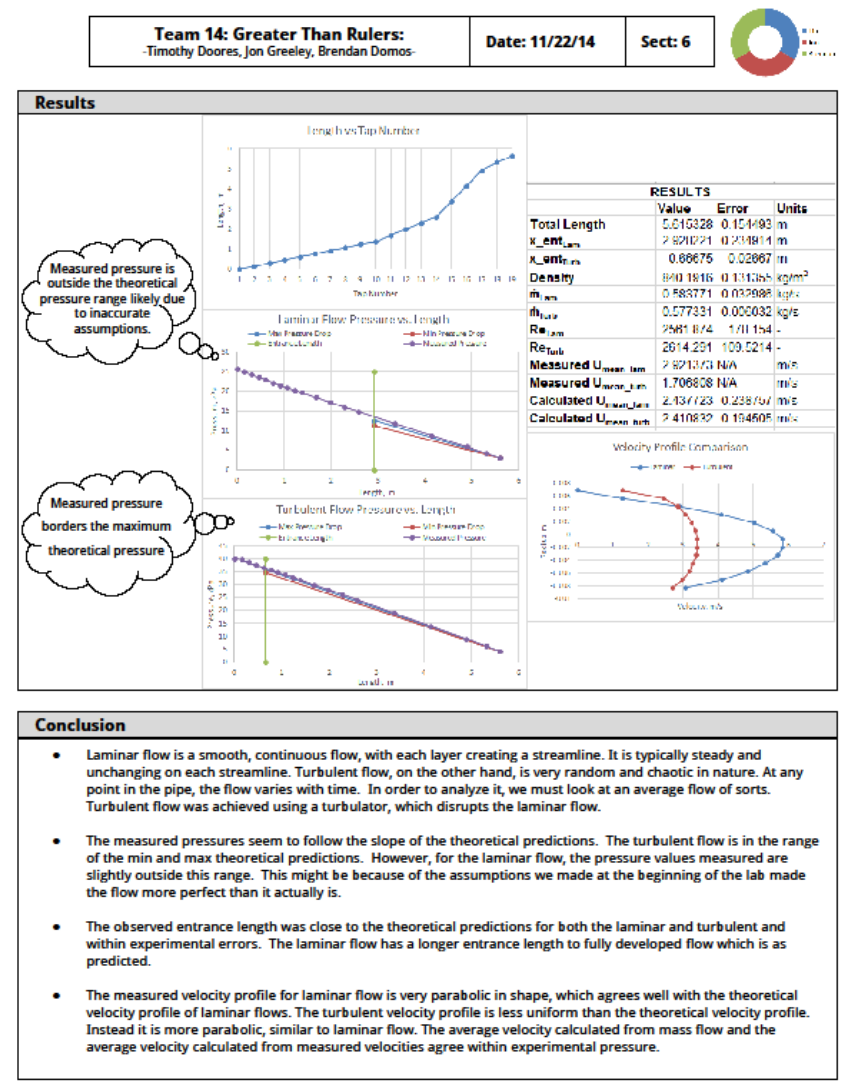

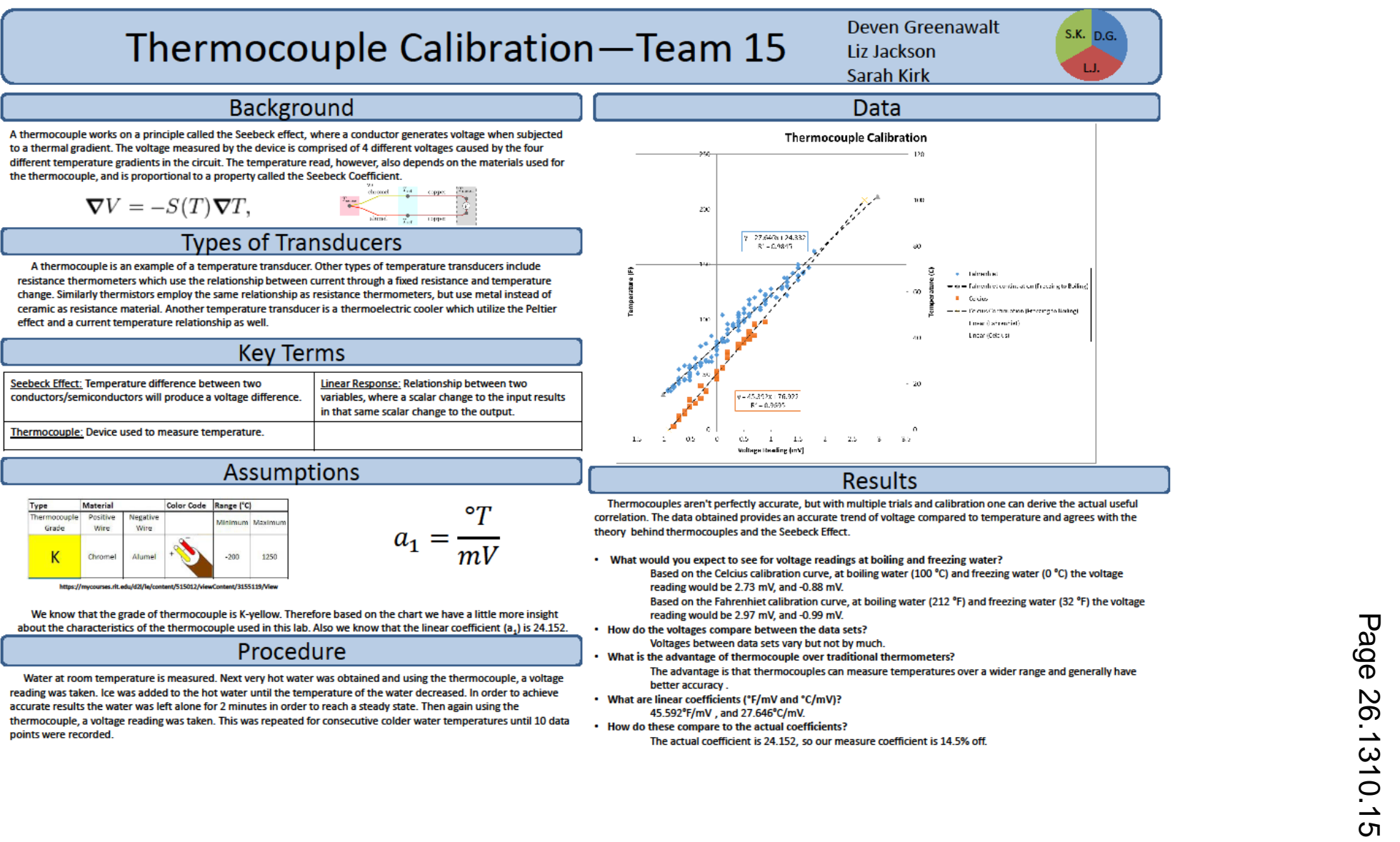




\section{Appendix C: Centrifugal Pump Prelab Activities}
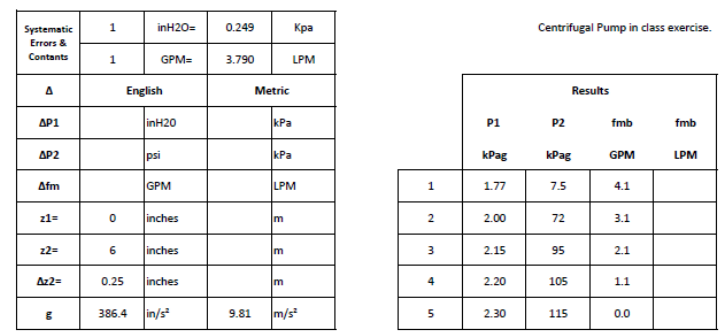

\begin{tabular}{|c|c|c|c|c|c|c|c|}
\hline & \multicolumn{4}{|c|}{ Random Error } & \multicolumn{3}{|c|}{ Net Error } \\
\hline & ${ }_{\mathrm{K} P \mathrm{P}}^{\mathrm{P}}$ & ${ }_{\mathrm{PPg}}^{\mathrm{P}}$ & $\begin{array}{l}\mathrm{fmb} \\
\mathrm{GPM}\end{array}$ & $\begin{array}{l}\mathrm{fmb} \\
\mathrm{LPm}\end{array}$ & $\begin{array}{l}{ }^{\mathrm{P} 1} \\
\text { kPag }\end{array}$ & ${ }_{\mathrm{k} P \mathrm{P} g \mathrm{~g}}^{\mathrm{P}}$ & $\begin{array}{l}\text { Imb } \\
\text { tlom }\end{array}$ \\
\hline 1 & 0.00 & 0.5 & 0.0 & & & & \\
\hline 2 & 0.03 & 3.0 & 0.0 & & & & \\
\hline 3 & 0.03 & 1.0 & 0.0 & & & & \\
\hline 4 & 0.05 & 1.0 & 0.0 & & & & \\
\hline 5 & 0.01 & 5.0 & 0.0 & & & & \\
\hline
\end{tabular}

\begin{tabular}{|c|c|c|c|c|}
\hline & \multicolumn{4}{|c|}{ Data to be plotted } \\
\hline & Head & SHead & flow & Aflow \\
\hline & m & m & IPM & LPM \\
\hline 1 & & & & \\
\hline${ }^{2}$ & & & & \\
\hline 3 & & & & \\
\hline 4 & & & & \\
\hline 5 & & & & \\
\hline
\end{tabular}
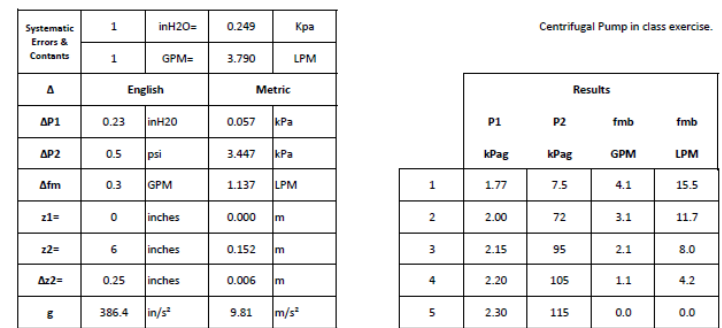

\begin{tabular}{|c|c|c|c|c|l|l|l|}
\cline { 2 - 8 } \multicolumn{1}{c|}{} & \multicolumn{4}{c|}{ Random Error } & \multicolumn{3}{c|}{ Net Error } \\
\cline { 2 - 8 } \multicolumn{1}{c|}{} & $\begin{array}{c}\text { P1 } \\
\text { kPag }\end{array}$ & $\begin{array}{c}\text { P2 } \\
\text { kPag }\end{array}$ & $\begin{array}{c}\text { fmb } \\
\text { GPM }\end{array}$ & $\begin{array}{c}\text { fmb } \\
\text { LPM }\end{array}$ & \multicolumn{1}{c|}{$\begin{array}{c}\text { P1 } \\
\text { kPag }\end{array}$} & $\begin{array}{c}\text { P2 } \\
\text { kPag }\end{array}$ & $\begin{array}{c}\text { fmb } \\
\text { LPM }\end{array}$ \\
\hline 1 & 0.03 & 0.5 & 0.0 & 0 & 0.0646877 & 3.4834494 & 1.137 \\
\hline 2 & 0.03 & 3.0 & 0.0 & 0 & 0.06468872 & 4.5699474 & 1.137 \\
\hline 3 & 0.03 & 1.0 & 0.0 & 0 & 0.0646872 & 3.5894874 & 1.137 \\
\hline 4 & 0.05 & 1.0 & 0.0 & 0 & 0.0760555 & 3.55944874 & 1.137 \\
\hline 5 & 0.01 & 5.0 & 0.0 & 0 & 0.0581759 & 6.0732544 & 1.137 \\
\hline
\end{tabular}

\begin{tabular}{|c|l|l|l|l|}
\cline { 2 - 5 } \multicolumn{1}{c|}{} & \multicolumn{4}{c|}{ Data to be Plotted } \\
\cline { 2 - 5 } \multicolumn{1}{c|}{} & \multicolumn{1}{c|}{$\begin{array}{c}\text { Head } \\
\mathrm{m}\end{array}$} & \multicolumn{1}{c|}{$\begin{array}{c}\text { AHead } \\
\mathrm{m}\end{array}$} & \multicolumn{1}{c|}{$\begin{array}{c}\text { flow } \\
\text { LPM }\end{array}$} & \multicolumn{1}{c|}{$\begin{array}{c}\text { Aflow } \\
\text { LPM }\end{array}$} \\
\hline 1 & 0.7364979 & 0.3552097 & 15.54 & 1.137 \\
\hline 2 & 7.2879759 & 0.4659358 & 11.75 & 1.137 \\
\hline 3 & 9.6172318 & 0.3660154 & 7.96 & 1.137 \\
\hline 4 & 10.631503 & 0.3660381 & 4.17 & 1.137 \\
\hline 5 & 11.640677 & 0.6191491 & 0.00 & 1.137 \\
\hline
\end{tabular}

Blank sheet provided for in lab hand calculations shown with and without results

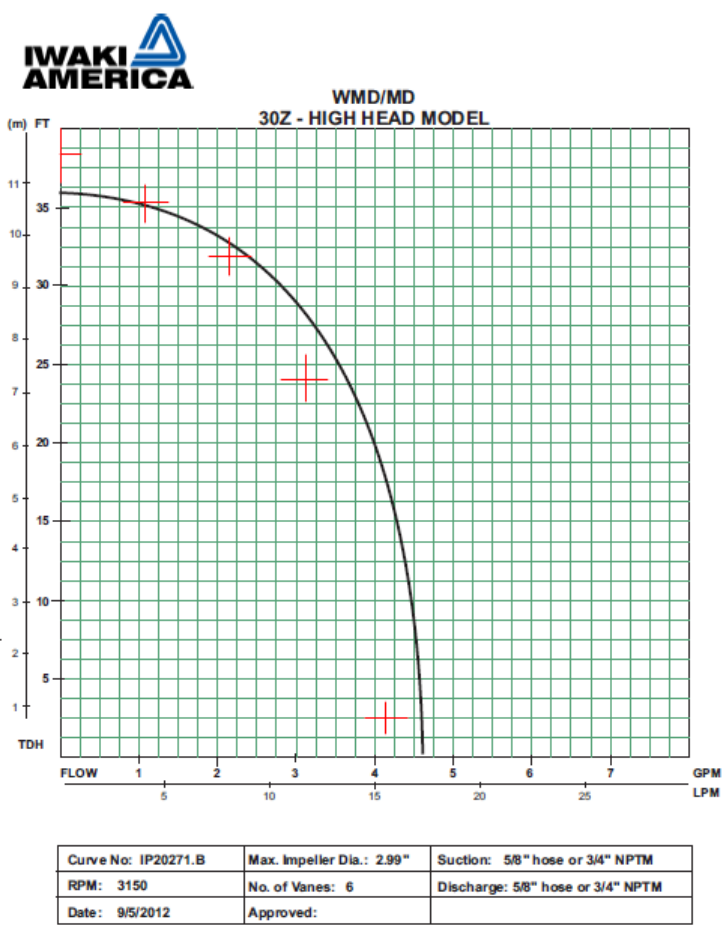

Students are asked to use the recorded data with uncertainty measurements to determine the head with uncertainty and the flow with uncertainty. Results are plotted on top of the manufacturer supplied pump curve as shown. 


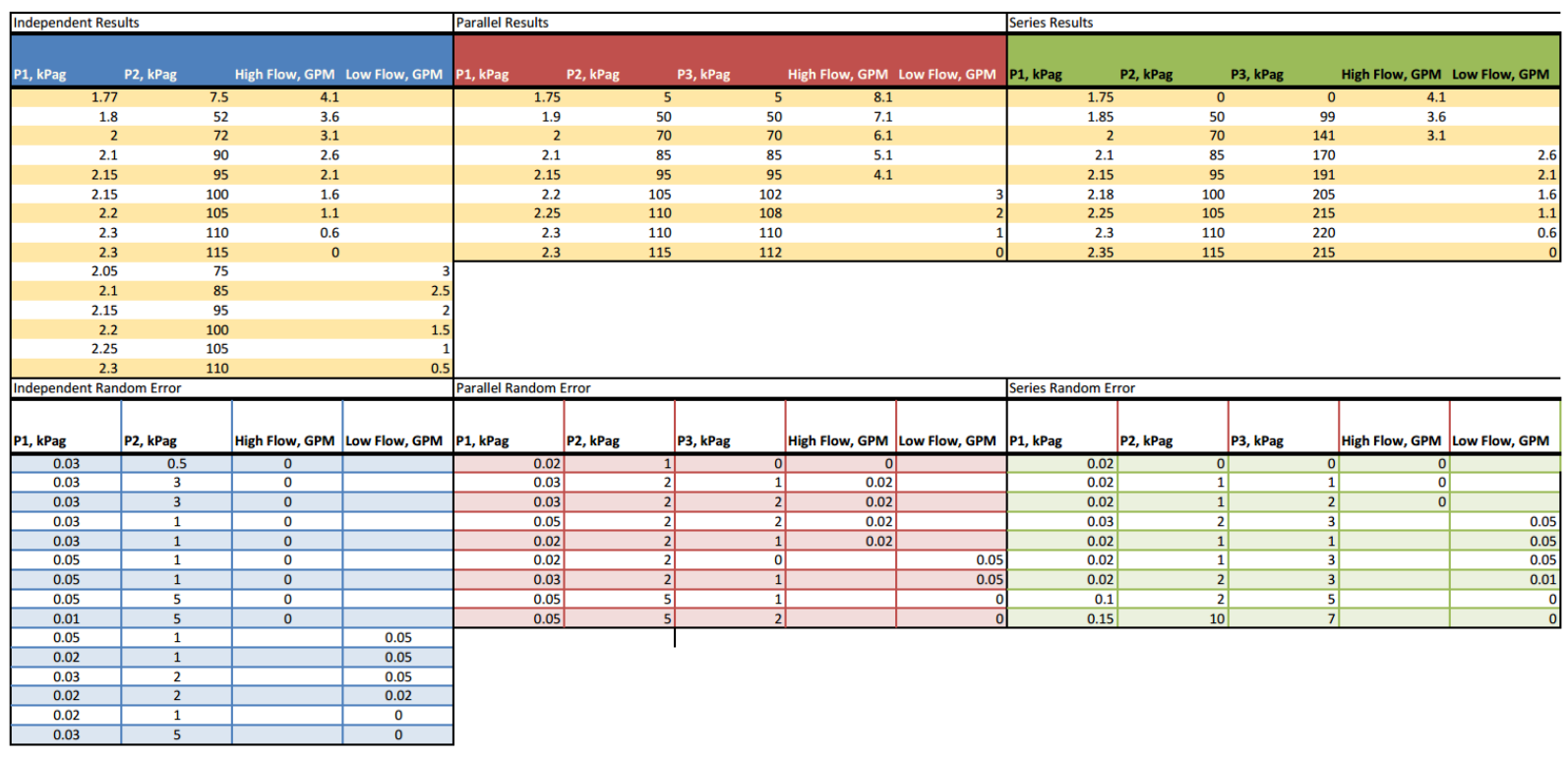

Full set of provided data for development of required spreadsheet and plots
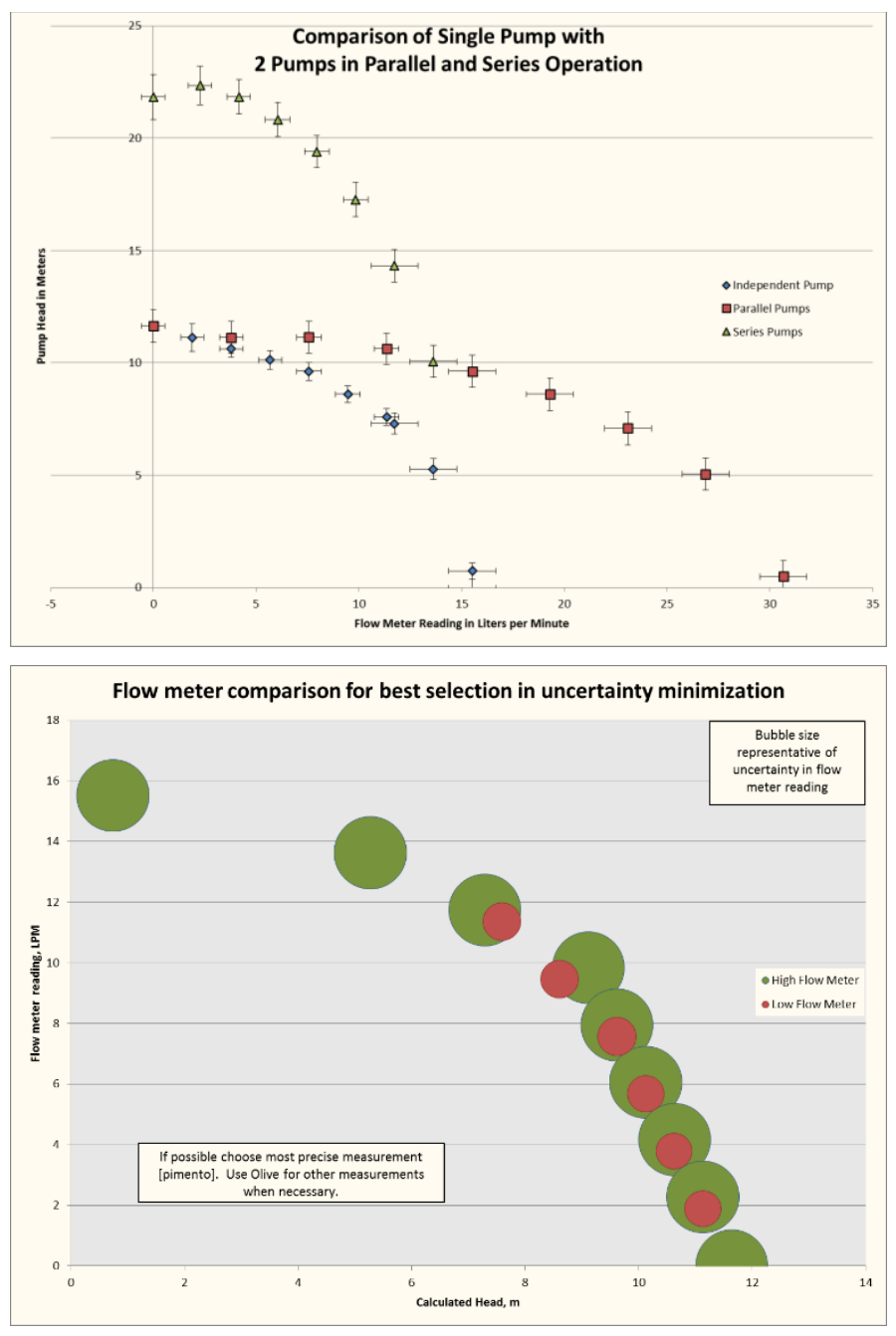

Students are asked to calculate the head and flow based on the recorded values. Students are also asked to determine the net uncertainty based on recorded random uncertainty and instrument systematic uncertainty.

The top plot is a comparison of the pump configurations.

The bottom plot is a comparison of two sized flow meters over the same ranoe 